Article

\title{
Sustainability Evaluation on the Grain to Green Program in the Hexi Corridor of China: A Metacoupled System Perspective
}

\author{
Jian Zhang ${ }^{1}$, Tao Tian ${ }^{1}$, Jinying Cui ${ }^{1}$, Gordon M. Hickey ${ }^{2}$, Rui Zhou ${ }^{3}{ }^{(}$, Jianguo Liu ${ }^{4} \oplus$ and Youcai Xiong ${ }^{1} * *(\mathbb{D}$ \\ 1 State Key Laboratory of Grassland Agro-ecosystems, The Institute of Agro-ecology, School of Life Sciences, \\ Lanzhou University, Lanzhou 730000, China; zigo4732@163.com (J.Z.); tiant1992@163.com (T.T.); \\ jinying_cui@163.com (J.C.) \\ 2 Department of Natural Resource Sciences, McGill University, Macdonald Campus, 21111 Lakeshore Road, \\ Ste-Anne-de-Bellevue, QC H9X 3V9, Canada; gordon.hickey@mcgill.ca \\ 3 School of Ecology and Environmental Science, Yunnan University, Kunming 650091, China; \\ zhour@ynu.edu.cn \\ 4 Center for Systems Integration and Sustainability, Department of Fisheries and Wildlife, \\ Michigan State University, East Lansing, MI 48823, USA; liuji@msu.edu \\ * Correspondence: xiongyc@lzu.edu.cn; Tel./Fax: +86-931-8914-500
}

check for updates

Citation: Zhang, J.; Tian, T.; Cui, J.; M. Hickey, G.; Zhou, R.; Liu, J.; Xiong, Y. Sustainability Evaluation on the Grain to Green Program in the Hexi Corridor of China: A Metacoupled System Perspective. Sustainability 2021, 13, 1498. https://doi.org/ $10.3390 /$ su13031498

Academic Editor: Andreas Angelakis Received: 15 November 2020 Accepted: 29 December 2020 Published: 1 February 2021

Publisher's Note: MDPI stays neutral with regard to jurisdictional claims in published maps and institutional affiliations.

Copyright: (c) 2021 by the authors. Licensee MDPI, Basel, Switzerland. This article is an open access article distributed under the terms and conditions of the Creative Commons Attribution (CC BY) license (https:// creativecommons.org/licenses/by/ $4.0 /)$.

\begin{abstract}
Most previous studies aim to predict ecosystem sustainability from the perspective of a sole human or natural system and have frequently failed to achieve their desired outcome. Based on the coupled human and natural system (CHANS) and its interaction with other systems, we attempted to analyze the effectiveness of the Grain to Green Program and predict future trends in the Hexi Corridor, the hub of the ancient silk road of China. At different scales, we applied a metacoupling framework to investigate the flows, effects, and causes of the complex CHANS. Three typical inner river watersheds within the corridor at three different geographic scales (local, regional and national) were estimated and compared. The Telecoupling Geo App, additional models, and software tools were employed to evaluate the CHANS series of the focal system (Hexi Corridor, local), adjacent system (Gansu Province, regional), and distant system (China, national). The results showed that most flows can be screened and quantitatively analyzed across focal, adjacent and distant systems. The social and economic transformations in adjacent and distant systems could affect the possibility and whereabouts of labor transfer in the focal system. Moreover, the labor migration increased the implementation efficiency of the Grain to Green Program as a Payment for Ecosystem Services (PES) strategy, thereby improving its ecological benefits. For the first time, we established a metacoupled model to quantitatively evaluate aspects of ecosystem sustainability in China, providing insight to the theory and application of sustainability science.
\end{abstract}

Keywords: metacoupled system; payment for ecosystem service; water yield; labor migration; flows

\section{Introduction}

Global ecosystem services are being threatened at an unprecedented level [1]. Among potential responses, the Payment for Ecosystem Services (PES) Program has been extensively accepted as a critical strategy of ecosystem conservation [2-4]. PES is a tool for protecting the methods of actively managing ecosystems to produce environmental services. The incentives can be used to compensate those who currently provide environmental services, or to motivate those who do not provide environmental services [5]. To assess the effectiveness of PES, several existing studies have been conducted to reveal the impacts of PES on environmental and socioeconomic outcomes, yet most of them were performed qualitatively [6-8]. In 2015, the United Nations launched the 2030 Agenda for Sustainable Development, outlining 17 sustainable development goals (SDGs). Over the last two decades, the publications regarding "sustainability" have boomed, making people often view "sustainability science" as a different field [9]. Though "sustainability" is of high importance, it is difficult to evaluate sustainability in a coupled ecosystem $[10,11]$. 
From the perspective of Human and Environment Systems, the sustainable use of resources is considered one of the major challenges facing humanity [12,13]. A wide range of ecosystem services are frequently offered by complying with the links between ecosystem and complex human system with embedded social, political, economic, and cultural components. It is noteworthy that they are multi-scale, spatially heterogeneous, time-varying, highly path-dependent, extensively adaptive, and subjected to internal and external effects [14]. Under such complexity, most of the existing efforts have been devoted to engineering and technical aspects, yet few have emphasized socio-economic aspects, and even fewer have coupled human and natural systems at different scales.

Recently, a new scientific paradigm, the Telecoupled System Framework, has been proposed to enable simultaneous assessment of socio-economic and environmental interactions between local and distant areas [15]. The Telecoupling Framework is conceptually recognized as a novel method for system integration, a logical extension of the study of coupled human and natural systems (CHANS). Based on system integration, the interactions occur in specific geographic locations, as well as in globalization, particularly referring to long-distance and cross-mode system interactions [16]. To assess the sustainability of an ecosystem and its management strategy, the interactions between environmental and socio-economic dimensions in multiple CHANS need to be studied comprehensively [17]. In general, the multiple CHANS consists of five related components: system, agent, flow, cause, and effect [18]. In recent decades, the framework of telecoupling has been applied to help tackle several vital problems, including, international trade (e.g., food, forest products, energy [7,17,19]), species invasions [15,19], global land grabbing and investment [17], global land use, and distant ecosystem services [20-22].

To reconcile the conflict between ecosystem conservation and social-economic development, PES programs have been rolled out in China for years. Related investigations were mainly aimed at exploring the effects of ecological compensation policies. Li and his colleagues investigated the influence of the policy of returning grain for 'green' on the livelihoods of local farmers based on the Gini coefficient model in the Zhouzhi County in Shaanxi Province of China [23]. Cao et al. [24] also have analyzed the impacts exerted by natural forest protection projects on local farmers' income. Both case studies showed that from the perspective of harmonious development of social economies and ecological protection, any one-sided emphasis on economic development goal or ecological protection would be biased and may cause new problems (e.g., unreasonable allocation of resources). For the management of fragile ecosystems, it was necessary to predict the sustainability of the ecosystem based on a single or local CHANS. However, the predictions failed to achieve the desired outcome, and most of them resulted in qualitative assessment rather than quantitative exploration. Given the complexity of the sole CHANS interaction with other systems, the Grain to Green Program was devised to restore natural ecosystems in northwest China. The Grain to Green is viewed as the largest PES project in history.

Unreasonable human activities are known to result in ecological disaster under increasing population. Following severe droughts in 1997 and massive flooding in 1998, China implemented several large-scale forestry and environmental conservation projects exhibiting unique scales, durations, and investments ( $>700$ billion RMB over the past decade) [25]. Programs included enlarging existing conservation areas and establishing new ones, specifically for ecosystem service provision, as well as two national PES programs: the Grain to Green Program (GTGP) and the Natural Forest Conservation Program (NFCP) [23]. The pilot of the GTGP began in Sichuan, Shaanxi, and Gansu provinces in 1999, and was then expanded to 17 provinces in 2000, and further to 25 provinces in 2002 [25]. Due to its major objective to reduce soil erosion, the criterion for program enrollment was aimed at the slope cropland conversion, for those with a steepness above $15^{\circ}$ in northwest China and above $25^{\circ}$ elsewhere in China. Though the croplands with the slopes above the threshold received priority in enrollment, a considerable amount of cropland plots with slopes below the threshold can be enrolled as well [26]. Farmers enrolling and converting cropland have received conservation payments for two years with respect to pasture, five years for 
'economic' forests that can be harvested for something other than wood (e.g., fruit trees), or eight years for 'ecological' forests, which can be harvested for wood. Among various land conversions, most $(>75 \%)$ of enrolled croplands were converted into 'ecological' forests. The annual conservation payments were $2250 \mathrm{~kg}$ and $1500 \mathrm{~kg}$ of grain or cash payments of 3150 and $2100 \mathrm{RMB} \mathrm{ha}^{-1}$ (at a rate of $7.3 \mathrm{RMB}$ to 1 USD in 2011) of enrolled cropland. By the end of 2011, the GTGP-enrolled croplands had primarily fulfilled their contracts, and the program was extended for another decade based on a range of conservation payments. Under the extended contract, the annual conservation payments would be half of the payments in the initial program, while annual miscellaneous expenses of $300 \mathrm{Yuan} \mathrm{ha}^{-1}$ remained unchanged. In this study, we chose the Qilian Mountains as a typical case site to address the sustainability evaluation of the Grain to Green Program.

\section{Materials and Methods}

\subsection{Study Area}

The study area, the Qilian Mountains, is located between $97^{\circ} 25^{\prime}-103^{\circ} 46^{\prime}$ E, $36^{\circ} 43^{\prime}-$ $39^{\circ} 36^{\prime} \mathrm{N}$, covering an area of 2653 thousands ha. There are three basins around the Qilian Mountains, that is, the Heihe Basin, Shiyang River Basin, and Shule River Basin, respectively (Figure 1). The Qilian Mountains lie in the northeastern margin of the QinghaiTibetan Plateau forming a border between China's Gansu and Qinghai provinces. They are surrounded by the Loess Plateau and the Mongolia Plateau and are incorporated into several parallel mountain chains. From 1986 to 1998, the forest land located in the eastern mountain range of Qilian Mountains was gradually reduced, part of which was converted to grassland. As a result of people's excessive logging, the woodland in the northern region has degraded to grassland on Gobi [27]. In the late 1990s, the GTGP was initiated as a PES practice. The households participating in the program can receive payments from the Chinese government to cover the economic loss created by abandoning croplands. This program has been extended gradually from the late 1990s to 2014, and has converted nearly nine million hectares from cropland to forest or grassland [1,22]. According to the public data, the NDVI of Qilian Mountains' vegetation tended to increase from 2000 to 2012, and the most obvious improvement was found in spring vegetation, while the changes in vegetation cover varied from different seasons. In addition, summer vegetation was observed to increase year by year in most areas, followed by spring vegetation, while autumn vegetation fluctuated slightly [28].

\subsection{Telecoupling Geo App}

The Telecoupling Geo App refers to an application, which is part of a collection of software and applications termed: 'Telecoupling Toolbox' [29]. Telecoupling Toolbox consists of two main existing products, specifically ArcGIS Toolbox and Geo App. ArcGIS Toolbox is equipped with a set of custom geoprocessing tools for use with ESRI ArcGIS Desktop, while Geo App provides a dynamic, interactive Web GIS platform with extensive mapping and analysis tools to systematically study telecoupling. Both Geo App and ArcGIS Toolbox are developed in a modular fashion to integrate with existing third-party tools (e.g., the InVEST model $[16,30])$, and additional telecoupling with the external application requirements are growing to fit the development of customized tools and models. All sample data and documentation are available for free and hosted in a public online repository (https://msu-csis.github.io/telecoupling-toolbox/). 


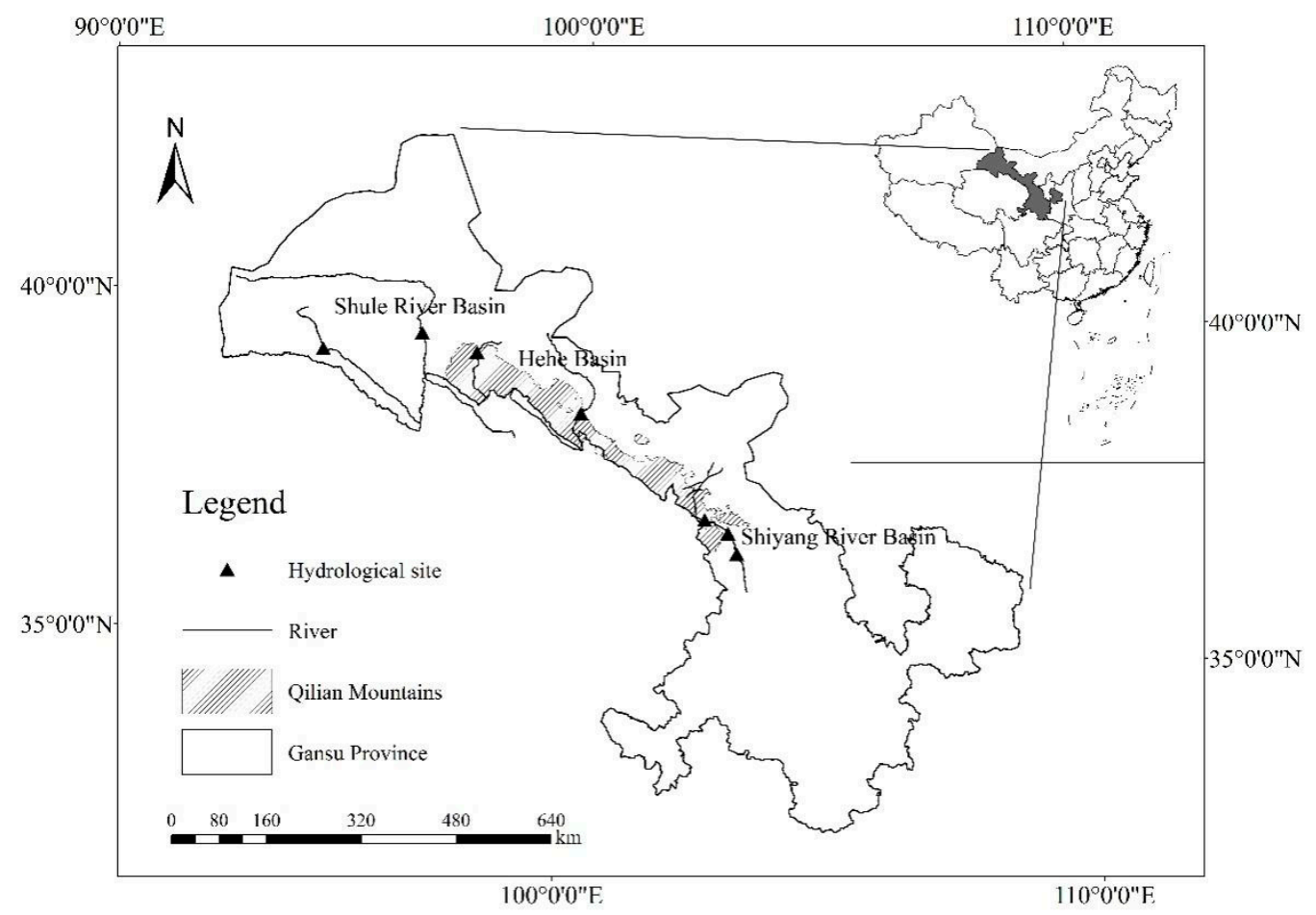

Figure 1. Study area and hydrological sites.

Telecoupling Geo App (https:/ / telecoupling.msu.edu/geo-app) is customized using one of ESRI's Web App Builder Developer Edition templates and deployed on Amazon Web Services (AWS), which is a computationally friendly environment enabling efficient data management and large-scale analysis. The identical virtual server acts as a web application layer and a GIS web services layer to store and offer public-facing geoprocessing services. It has Elastic Load Balancing (ELB) services and auto-scaling set up to automatically route incoming web traffic to an ever-changing Elastic Compute Cloud (EC2) instance by complying with user needs. Furthermore, the Geo App has been developed in a modular fashion to facilitate the integration with existing third-party tools (e.g., InVEST model), as well as accommodate the development of custom tools and models with the demand for additional telecoupling applications.

\subsection{InVEST Model and Climate Data}

The effect of landscape management on seasonal flow is critical to watershed management, and it also affects the water conservation in surrounding areas outside the target area, but this impact depends on several environmental factors including climate, soil, vegetation, slope, and position along the flow path (verifying whether the pixel may receive water from upslope or if water recharged may later be evapotranspired). The water flowing across the landscape is either evaporated, transpired, withdrawn by a well, or leaves the watershed as deep groundwater flow or stream flow. If an individual pixel and its value with respect to water yield are considered, two approaches can be used.

The first variable gives credit to the net amount of water generated on a pixel equated with the incoming precipitation minus the losses to evapotranspiration on that pixel. In such a scheme, it is possible for actual evapotranspiration to be greater than precipitation if water is supplied to the site from up gradient. Thus, the net generation could be negative. This approach places little stress on the eventual disposition of water generated on that pixel; that is, it does not consider whether the water actually shows up as stream flow or is evaporated or withdrawn somewhere along its path. The second approach gives credit to the water from a parcel that actually shows up as stream flow. Thus, if a parcel generates water that is later evaporated, the contribution is considered nil. 
In the present study, the impact and changes under the GTGP were analyzed in the Qilian Mountains as a case study. The Qilian Mountains area is therefore referred to as the center of our research (focal system), and the flows between the surrounding areas and other relevant areas (adjacent system and distant system) were analyzed. Furthermore, the InVEST model was adopted to analyze the water conservation and water flows in the Qilian Mountains and their surrounding areas. The data applied in the InVEST model are listed in Table 1 (the land-use/land-class data, climate data, DEM data as well as soil group data).

Table 1. Data sources for the seasonal water yield of InVEST model.

\begin{tabular}{|c|c|}
\hline Coding & Data \\
\hline$P_{i, m}$ & $\begin{array}{l}\text { The annual and monthly precipitation, respectively }(\mathrm{mm}) \text {. The data is from the Chinese } \\
\text { National Meteorological Information Center (http:// data.cma.cn/). The year data is } \\
\text { summarized and analyzed according to the data of each month of } 12 \text { months, and the } \\
\text { difference calculation is performed every year. } 12 \text { months of raster data. }\end{array}$ \\
\hline $\mathrm{ET}_{0, \mathrm{~m}}$ & $\begin{array}{l}\text { The evapotranspiration data is derived from the CGIAR CSI dataset based on World } \\
\text { Clim data (http:/ / www.cgiar-csi.org/data/global-aridity-and-pet-database), based on } \\
\text { a year of } 12 \text { months. }\end{array}$ \\
\hline DEM & $\begin{array}{l}\text { The data is from the Resource and Environment Data Cloud Platform of China } \\
\text { (http://www.resdc.cn/), and the spatial resolution is } 1 \mathrm{~km} \text {. }\end{array}$ \\
\hline LULC & $\begin{array}{l}\text { The key component for the water model is a spatially continuous land-use/land-class } \\
\text { raster grid. That is, within a watershed, all land-use/land-class categories should be } \\
\text { defined. The land-use data is from the University of Maryland's Global Land Cover } \\
\text { Facility (http:/ /glcf.umd.edu/data/landcover/). This spatial resolution of the data is } \\
1 \mathrm{~km} \text {. } \\
\text { The simplest categorization of LULCs on the landscape involves delineation by land } \\
\text { cover only (e.g., cropland, temperate conifer forest, and prairie). Several global and } \\
\text { regional land cover classifications are available, and often detailed land cover } \\
\text { classification has been done for the landscape of interest. In our study, data analysis was } \\
\text { performed based on the most basic classification. }\end{array}$ \\
\hline $\begin{array}{l}\text { Soil } \\
\text { group }\end{array}$ & $\begin{array}{l}\text { The soil group is determined by hydraulic conductivity and soil depth. Future Water } \\
\text { created a global hydraulic map } \\
\text { (http:/ / www.futurewater.eu/2015/07/ soil-hydraulic-properties/). }\end{array}$ \\
\hline
\end{tabular}

\subsection{Understanding the Metacoupled System}

A metacoupled system is a set of coupled systems that interact internally as well as nearby and far away, facilitated by agents affected by various causes with various effects [31]. To account for the interactions within a system boundary, as well as those nearby and far away, the concepts and frameworks of focal, adjacent, and distant systems are proposed. The definition of focal system is determined by a number of factors such as research goals, objectives, questions, and feasibility including data availability and logistics. The distant system and the focal system are directly related to the core research events. An adjacent system is near the focal system.

Focal system: The focal system in the Qilian Mountains (Figure 2) largely consists of a social economic system and a natural ecosystem that is mainly composed of farmers. In such a system, there are considerable agents and factors (e.g., farmers' livelihood strategies and sources of income), which would change due to policy inputs and thus cause changes in the response of local farmers to policies, thereby affecting the types of land cover, biodiversity, and soil physical and chemical properties in the natural ecosystem. 


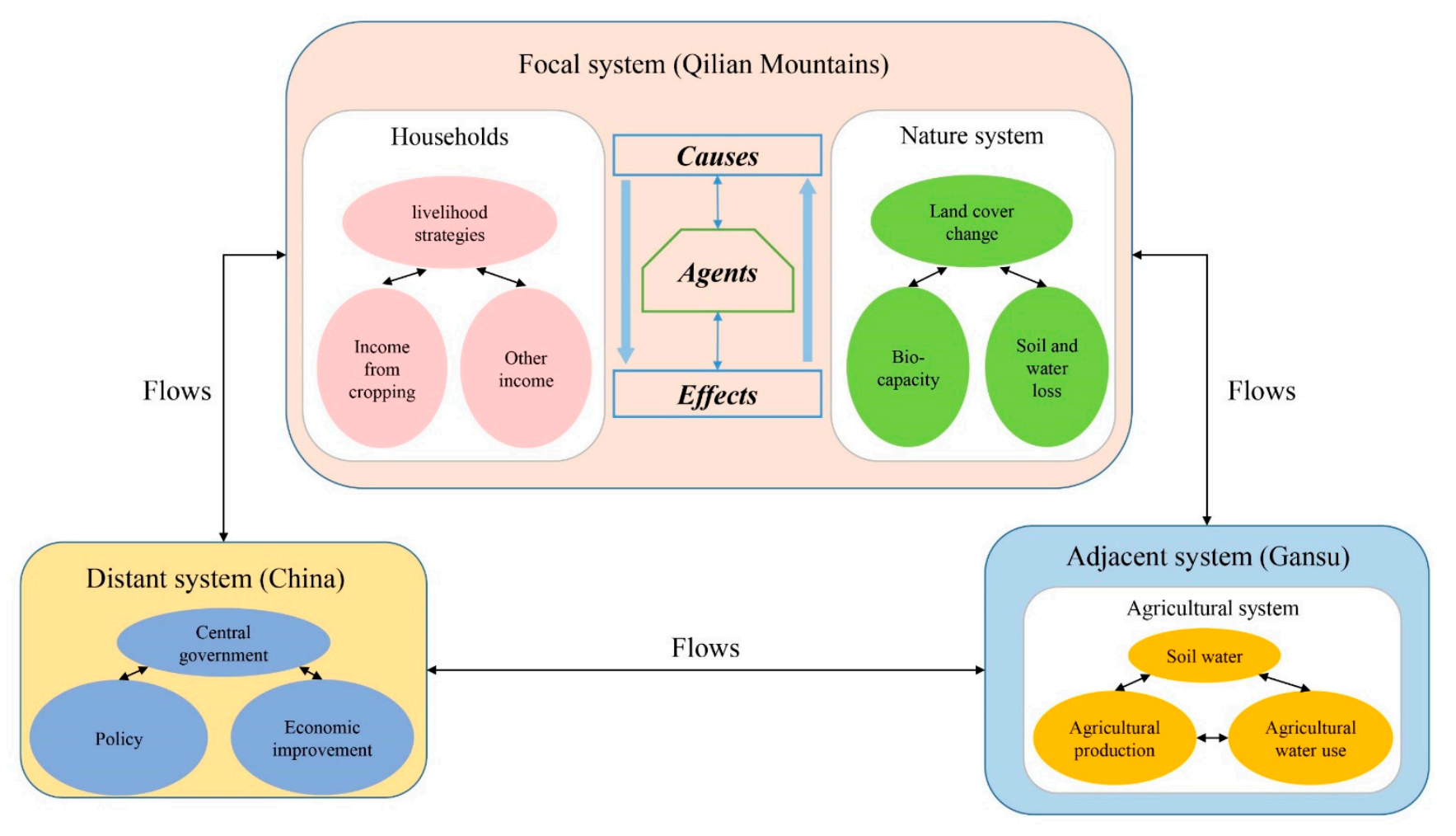

Figure 2. Metacoupled system of Qilian Mountains under the Grain to Green Program (GTGP).

Distant system: Regarding the rest of China (i.e., all areas except the focal and adjacent systems) as the distant system, this is mainly the policy supply of the central government and the provision of a large economic environment. The intervention of related policies will cause some changes to the focus system and the peripheral system.

Adjacent system: Peripheral system. The main peripheral system analyzed in this study is Gansu Province, specifically, the area around Qilian Mountain. Under some changes in the promotion of the policy of returning grain for green in the Qilian Mountains, it will also have a certain impact on the peripheral systems (e.g., the movement of labor and the change of water resources). The aforementioned will correspondingly cause agricultural water and agricultural production in the peripheral system.

The GTGP connects a range of systems. First, the Chinese government authorizes payments to release cultivated land from production. Specific to this activity, the Chinese government in Beijing established a system of payments and information presentation to farmers and local government actors in the Qilian Mountains within Gansu Province. After the farmers in the Qilian Mountains receive payments, they act as the receiving system. The effect of the payments is land cover change and a shift in socioeconomic outcomes as farmers adjust their behaviors. Particularly, farmers remove land from production allowing it to return to a natural state. In the process, outflows of ecosystem services are enhanced. With the outflows occurring, the Qilian Mountains become a sending system with the broader surrounding area, acting as the receiving system for ecosystem services (e.g., water flow and runoff).

The metacoupling framework was employed to assess the GTGP in the Qilian Mountains. Figure 2 indicates that Qilian Mountains act as the focal system. This primarily consists of the socio-economic system (Household) and the natural ecosystem. In such a system, there are many agents and factors. The rapid economic growth brought about by China's reform, opening up, and urbanization in the past 30 years has brought about an increase in labor demand. During policy promotion, ecological compensation has also given local residents vehicles to migrate, thereby the decrease in arable land area has brought great substitution effects to local farmers. Although the factors affecting labor 
transfer are different in different regions, the key lies in the main income method of local labor. The livelihood strategies and income sources of the household change because of the GTGP, thus affecting land cover types, bio-capacity, and chemical properties in the natural system. A total of more than 400 household interviews were conducted in the Qilian Mountains in 2015 in order to reveal the livelihood strategies. In our interview, we selected the households who participated in the GTGP. China is regarded as the distant system, as the central government of China supplies the program and the provides the economic environment. The involvement of relevant programs and policies cause the focal system and the adjacent system to change to some extent. To analyze the consequences of metacouplings beyond the focal system of this study, Gansu province (specifically three basins around the Qilian Mountains) was adopted as the adjacent system. Changes in the focal system (Qilian Mountains) will to a certain extent impact the adjacent system (e.g., the flow of labor migration, flow of water yield, and some impacts of soil moisture).

\section{Results}

\subsection{Flows in the Metacoupled System}

In general, different systems display different flows (e.g., information, energy and resources). In this study, we complied with the order of program occurrence according to the procedures of metacoupled system analysis. The distant system (China) first facilitated the program to the focal system (Qilian Mountains) via the information and payment flows. This resulted in changes to the livelihood of farmers and in the natural ecosystem of the focal system. With the implementation of the program, the households' feedback on the program changes to livelihood strategies tended to push forward labor migration and labor flows between different systems. A survey conducted in 2015 with households located in counties in the Qilian Mountains sought to disentangle the outcomes of the GTGP. In the survey questionnaire, the participants were asked about the movement of family members following ecosystem service payments.

The focal system was the critical water conservation area in the northwestern region, and to some extent modified the land type, rainfall, and runoff in the surrounding areas (adjacent system). Particularly, the Telecoupling Geo App was employed for further analysis. The In VEST model and the seasonal water yield module were adopted to calculate the distribution of water yields for the surrounding areas (Gansu Province) in 1980, 1990, 2005, 2010, and 2013 (Figure 3). The overall water yield distribution in Gansu Province proved to be relatively low in the northwest and high in the southeast. In the southeast region of study site, the overall water storage in the Gannan grassland and Tianshui appeared to be higher, and the water conservation was better than in other areas. At the time scale, the water yield of Gansu remained relatively stable from 1980 to 1990 . By the end of the 1990s, a series of serious sandstorm disasters took place in northwest China due to a large area of vegetation degradation and soil desertification, including the Qilian Mountains [32]. In the Qilian Mountains of northwest China, increasing population and unreasonable human activities had caused a sharp decrease in water conservation capacity of natural forests from 1980 to 2000. Due to the demand of agricultural development, local farmland area was increased by over $40 \%$. Regional vegetation cover and biodiversity were significantly affected by large-scale deforestation over two decades. In 2000, with economic development, the water yield dropped significantly. Since 2000, due to the implementation of the forest conservation policy, local water storage amount in Gansu Province was found to improve from $140 \mathrm{~mm}$ in 2000 to $195 \mathrm{~mm}$ in 2013. 


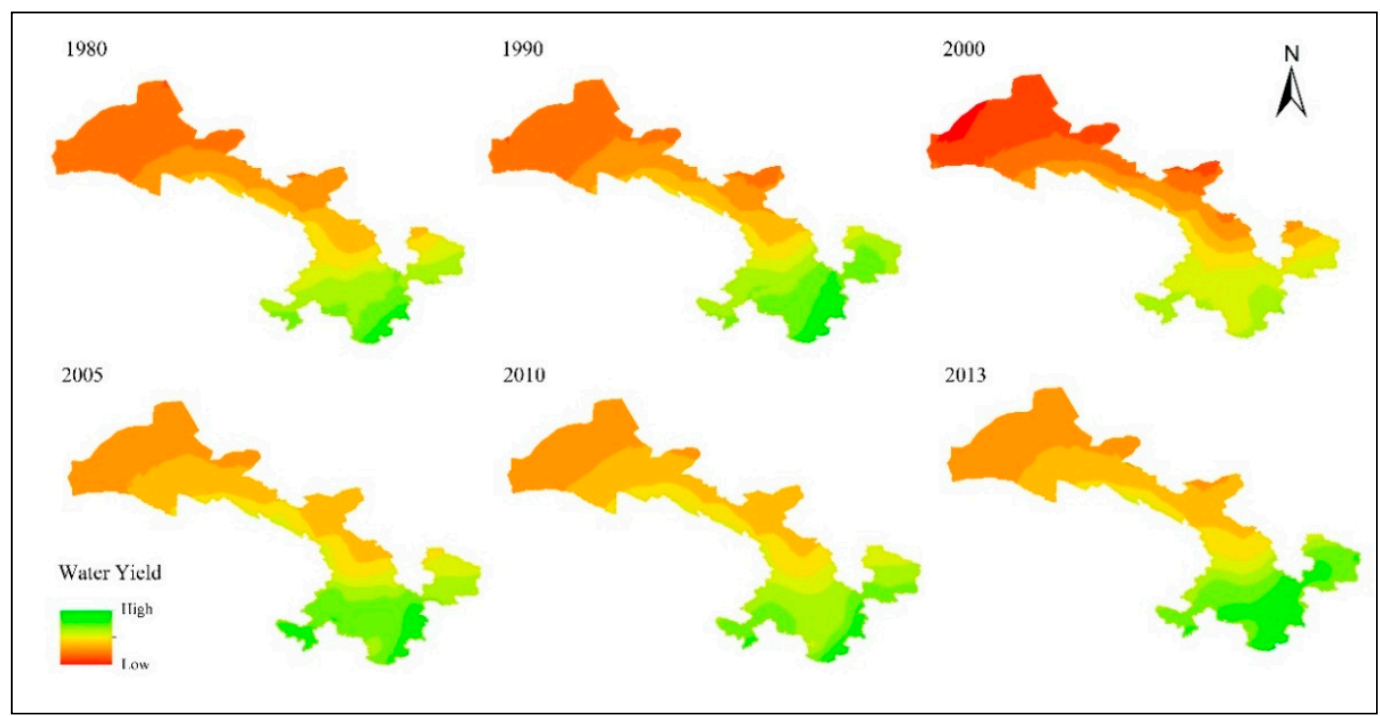

Figure 3. The map of water yield in Gansu (adjacent system).

\subsection{Causes in the Metacoupled System}

In the metacoupled system, the flows of water between the focal system (Qilian Mountains) and adjacent system (Gansu Province) represented one of the critical effects exerted by the labor migration. The labor migration can up-regulate the benefits of the GTGP and enhance the forest cover. It was noted that the study site was one of the vital water conservation areas in China, and local land cover change can reflect the improvements of forest effect and water yield. In addition, the land-use/land-class data indicated that the land uses of forest, shrub land, and grassland in Gansu Province increased by $7462.27 \mathrm{~km}^{2}$ during the period from 2000 to 2010 . According to the data of the survey, the conversion of farmland to forests was pronounced in the study site. Across one decade of the project implementation, the overall amount of grassland restoration was found to reach up to $6688.67 \mathrm{~km}^{2}$. Nearly $90 \%$ of the land changes were observed to originate from the GTGP practice. On the other hand, the Seasonal Water Yield model was employed in the Telecoupling Geo App to analyze the water yield in 2000, 2005, and 2010. In general, many aspects (e.g., precipitation, evapotranspiration, and land cover) were able to cause the changes in water yield.

Furthermore, the InVEST model was employed to calculate the results without land use type data. Also, the results derived from the original model were compared and calculated. The effects of the type changes on water yield were explored to obtain results (Figure 4). The data indicated that the changes in land use pattern were tightly associated with land use changes during the periods of 2000-2005 and 2005-2010. As revealed from Figure 4, the water yield was elevated from 2000 to 2005 as a result of land use changes in the western and southeastern Qilian Mountains. This tendency can represent the effect of the implementation of the GTGP in the Qilian Mountains. However, the land use changes only led to a slight impact on water yield from 2005 to 2010, when there was a declining trend in the forest and grassland area in the study site (Table 2). Across the two stages from 2000 to 2005 and from 2005 to 2010, the water yield capacity of the study site, particularly in the cities and towns within the site, tended to decline, possibly due to the acceleration of urbanization. 


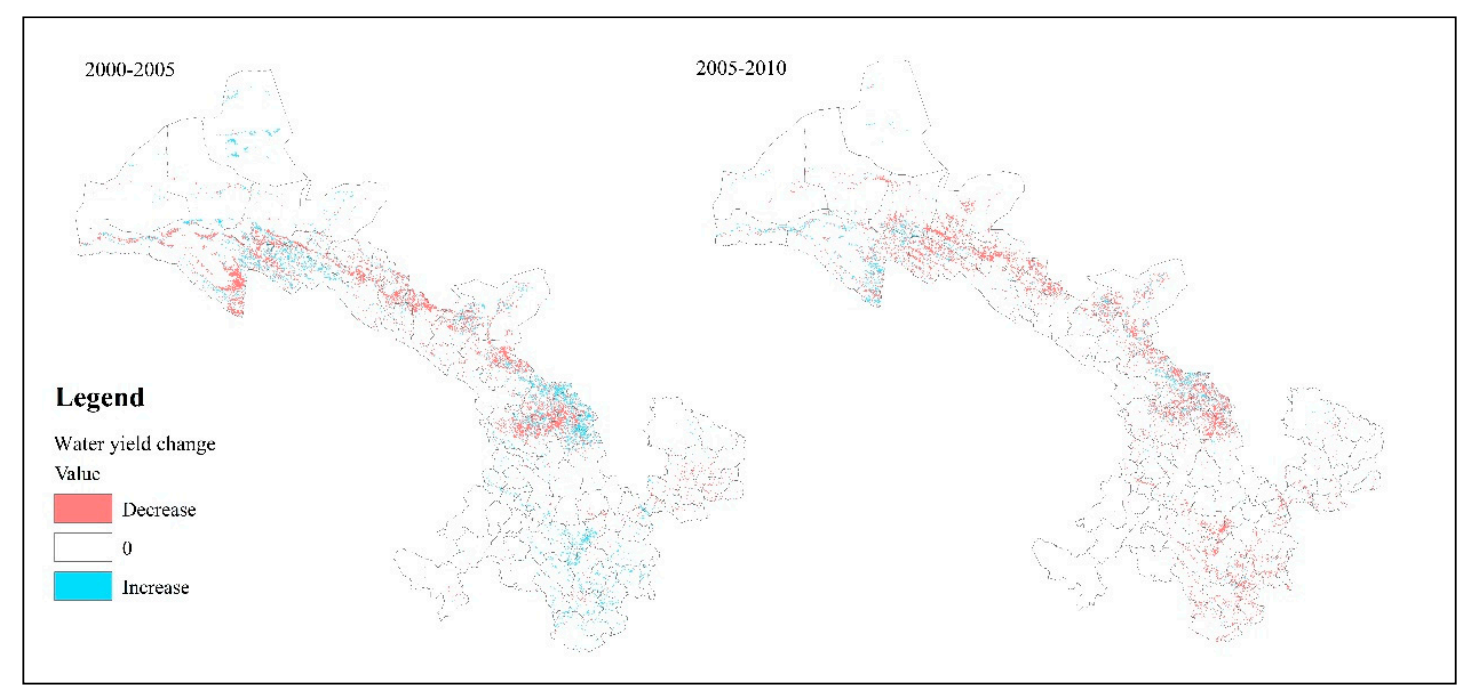

Figure 4. The change in water yield based on land-use/cover change.

Table 2. Changes in land use types from 2000 to 2010 in Gansu Province $\left(\mathrm{km}^{2}\right)$.

\begin{tabular}{ccccc}
\hline Land Use Type & $\mathbf{2 0 0 0}$ & $\mathbf{2 0 0 5}$ & $\mathbf{2 0 1 0}$ & Changes from 2000 to 2010 \\
\hline Water & 109.91 & 106.64 & 108.71 & -1.2 \\
Forest & $26,436.84$ & $30,837.26$ & $31,543.28$ & 5106.44 \\
Shrub lands & $10,083.01$ & $11,117.72$ & $10,891.49$ & 808.48 \\
Grassland & $181,821.8$ & $182,825.9$ & $183,369.2$ & 1547.35 \\
Wetlands & $23,981.46$ & $32,531.4$ & $34,485.01$ & $10,503.55$ \\
Croplands & 1738.90 & $17,38.93$ & 1738.61 & -0.29 \\
Urban and built-up lands & 2555.03 & 5463.8 & 6080.29 & $3525.26 \mathrm{x}$ \\
Non-vegetated lands & 179,073 & $161,178.3$ & $157,583.4$ & $-21,489.58$ \\
\hline
\end{tabular}

\subsection{Effects in the Metacoupled System}

As a result of the changes in land use/cover, local water conservation conditions in the focal system have undergone respective variations. Generally, the relevant changes in water conservation capacity affected the runoff conditions in the adjacent system. In the study site, three basins were selected around the Qilian Mountains for further analyses; specifically, Shiyang River Basin, Heihe Basin and Shule River Basin. The runoff was collected from 1960 to 2015 in the mentioned three basins. R/S analysis was conducted to reveal the continuous characteristics of annual runoff changes. The R/S analysis method is a statistical method for processing time series proposed by British hydrologist Hurst in 1951. R/S analysis has a predictive function for time series, and it plays an important role in fractal theory. R/S analysis is usually used to calculate the Hurst index in the fractal to further identify the dynamic trend of the time series. The results can be used to identify whether there existed similar or opposite changes in the runoff amount along with time scale (Figure 5). Given the historical trend of the three watersheds over the years, the Hurst indices of Shiyang River Basin, Heihe Basin, and Shule River Basin were 0.698, 0.569, and 0.929 , respectively, according to the results of $\mathrm{R} / \mathrm{S}$ analysis. The respective value was totally greater than 0.5 , indicating that the runoff of the mentioned three basins would increase in the future. Combined with the trend of runoff and Hurst index analysis, if climate change and human activities continued to develop at current rates, the runoff in the Shiyang River Basin would maintain a relatively stable trend in the future, and the runoff in the Heihe River Basin and the Shule River Basin would be elevated (Figure 5). 


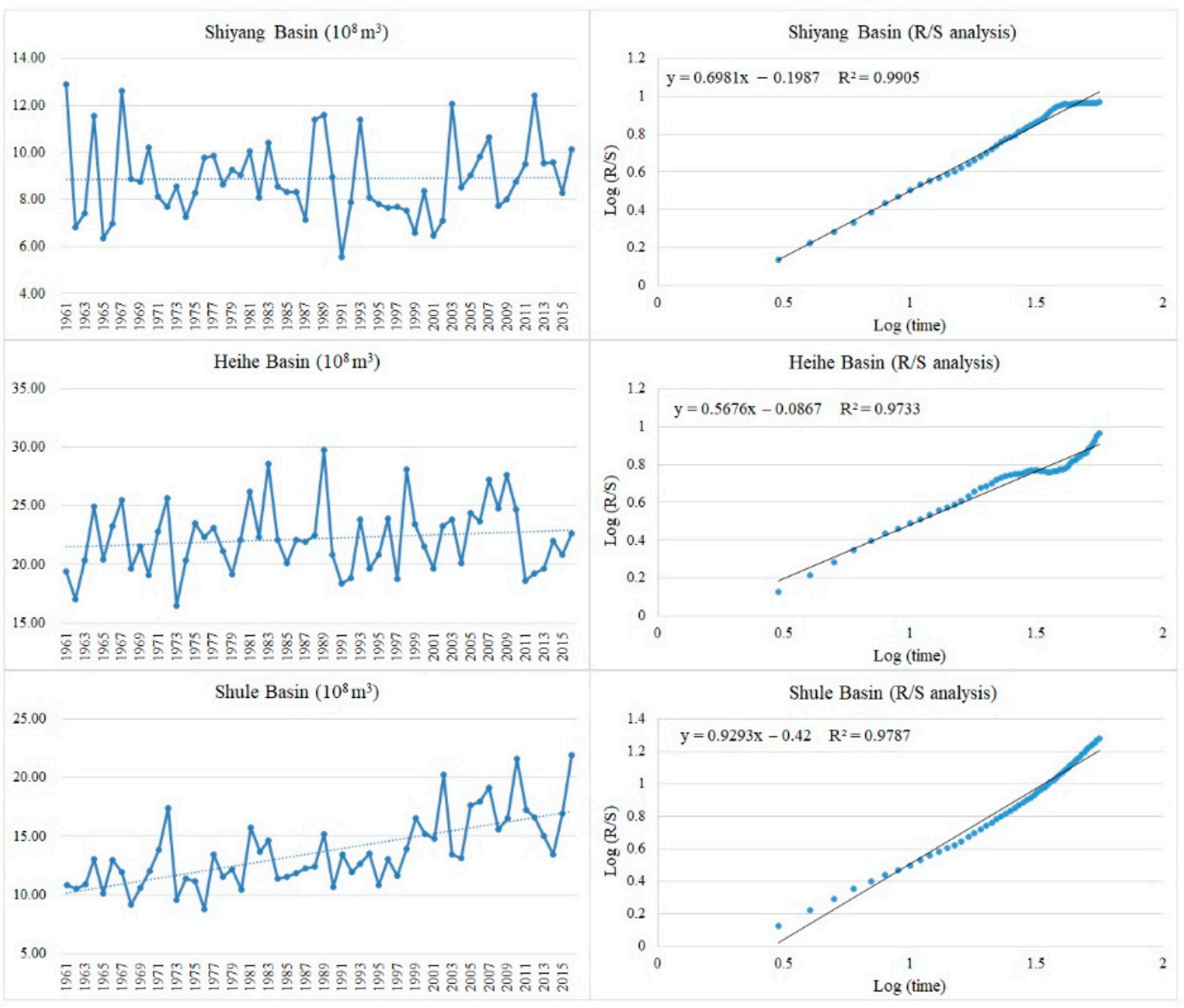

Figure 5. Change of the runoff and R/S analysis of runoff in three basins.

\section{Discussion}

The metacoupling framework can be a powerful tool to investigate socio-ecological systems based on a complex system approach [16]. By virtue of this framework, numerous components of the metacoupled system can be assessed, including socioeconomic and environmental changes and their cascading effects in local systems [31]. Any independent region can be considered a coupled human and natural system (CHANS) $[14,33,34]$. To reflect human-nature interactions from the perspectives of time and space [35], the framework of metacoupling (socioeconomic and environmental interactions over distances) can be constructed [15]. The telecoupling framework has already been applied to address several important issues, including international trade (e.g., food, forest products, energy $[7,17,19])$, species invasions [15,19], global land grabbing and investment [17], global land use, and distant ecosystem services [20-22]. In the present study, a metacoupled system was established based on the GTGP in the Qilian Mountains. We found that the GTGP implementation increased the vegetative cover by 32 million ha by 2010 , and converted 14.7 million ha of cropland to forest and grassland [6].

GTGP in the Qilian Mountains has many long-distance relationships. The social and economic development of the surrounding areas will affect the possibility and destination of local farmer labor migration. At the same time, the migration of local labor will affect the implementation and promotion of the policy, affecting the ecological benefits that the policy can achieve. In contrast, the flow of labor in the Qilian Mountains will affect the development of surrounding areas and complement each other. In the process of policy implementation and promotion, due to the increase in forest coverage in the Qilian 
Mountains, the water storage in the surrounding areas has been affected and there has been an upward trend. At the same time, it also affects the runoff conditions and the relative soil moisture content in the surrounding areas, which in turn affects the surrounding areas. The state of agricultural production is relatively stable in the region. On the basis of metacoupled system analysis, the effects of GTGP in Qilian Mountains on the surrounding areas were also investigated. With the expansion of forest area, the water conservation capacity of Qilian Mountain was improved, which resulted in an overall increase of water yield in surrounding areas. Accordingly, the increase in water yield massively improved the runoff of the surrounding basins. On the other hand, crop and livestock production has been substantially promoted as being affected by GTGP. Local farming practice became more intensive, since the production activities were focused on the much reduced available land areas [36,37]. Critically, the GTGP practice also promoted the labor transfer and changed the rural economic structure in the Qilian Mountains. Conversely, the adjustment of the rural economic structure stimulated farmers' income growth. Given the detected positive effects of labor transfer, economic adjustment, and income increase, a general implication is that the GTGP has been an effective strategy to restore local ecosystem, and therefore it can be sustained in the long run [38].

As for sustainable ecosystem management, the PES strategy is a valuable option to cope with the conflict between resource utilization and ecosystem conservation. In the Qilian Mountains, the PES program was capable of achieving various outcomes that impact both nearby and distant systems. In such a story map, the GTGP implementation was identified as a critical approach to affect land use decision-making and labor migration. The complex movements of individuals, goods, and information proved to accord with the characteristics required by the metacoupled system. Moreover, the Telecoupling Geo App, and its additional models \& software tools can be adapted to systematical analysis of the human and natural systems of the focal system (Qilian Mountains), adjacent system (Gansu Province) and distant system (China) under the GTGP. Based on the insights to proximate and distant interactions, essential information can be presented to help formulate policies for landscape sustainability. The Telecoupling Framework was used as a method to clarify the interaction between human and natural systems, and the socio-economic and environmental interactions in the distant relationship. It can also be employed to analyze the sustainable development of a region at different scales. In practice, this sort of system can provide valuable information and technological instruction for the design and implementation of ecosystem conservation programs. For example, the prediction derived from the system would be able to boost the long-term socioeconomic and environmental sustainability planning processes. However, future efforts should be made to enrich the variable types and their interactions for a more practical operation in fragile ecosystems. Statistical methodologies such as the factor analysis for mixed data tool helped describe potential factors that facilitate the flow of water between different systems. Although we acknowledge that true causality is difficult to determine in observational studies like the ones presented, it is nevertheless useful to look at potential factors associated with the flows of interest. For cases where empirical data sets are incomplete or missing, thus making it impossible to statistically determine potential factors, we recommend using the interactive tool within the Causes toolset to at least qualitatively describe them. Results showed that it is possible to quantify multiple direct socioeconomic and environmental effects, such as land use cover and water yield. Indirect effects and feedbacks that are indirectly related to the flow between telecoupled systems are harder to assess or tease apart from other factors.

\section{Conclusions}

For the first time, we applied a conceptual framework of metacoupling to assess the effectiveness of PES program and the sustainability of the severely degraded oasis ecosystem. Different flows were presented across focal, adjacent, and distant systems, which exhibited a high complexity from the perspective of CHANS. The social and economic transforma- 
tions in adjacent and distant systems could affect the possibility and whereabouts of labor transfer in the focal system. Moreover, the labor migration increased the implementation efficiency of the GTGP as a PES strategy, thereby improving its ecological benefits. Under the operation of the focal system, regional water yield (productivity) improved over the last two decades. Comparing with most previous qualitative investigations, our findings are based on quantitative analysis across different scales. Furthermore, a generalized predictive model was established in terms of ecosystem sustainability. If local climate change and human activities follow existing trends, the runoff in the Shiyang River Basin would maintain a relatively stable trend, whereas the runoff in the Heihe River Basin and the Shule River Basin seem likely to increase in the next decade. This model might open a window for future assessment and management of PES program in other similar regions under climate change.

Author Contributions: Y.X., G.M.H. and J.L. contributed to the conception of the study; J.Z., T.T. and J.C. performed the interview; J.Z., Y.X. and T.T. contributed significantly to analysis and manuscript preparation; J.Z. and Y.X. performed the data analyses and wrote the manuscript; R.Z. helped perform the analysis with constructive discussions. All authors have read and agreed to the published version of the manuscript.

Funding: The research was funded by International Cooperation Program of Ministry of Science and Technology of China (2015DFG31840), Natural Science Foundation of China (31570415) and National Specialized Support Plan for Outstanding Talents ("Ten Thousand People Plan").

Institutional Review Board Statement: Not applicable for studies not involving humans or animals.

Informed Consent Statement: Informed consent was obtained from all subjects involved in the study.

Data Availability Statement: Data is contained within the article.

Acknowledgments: We are grateful to the anonymous reviewers for their valuable suggestions and comments which helped to improve the manuscript.

Conflicts of Interest: The authors declare no conflict of interest.

\section{References}

1. Yang, H.; Yang, W.; Zhang, J.; Connor, T.; Liu, J. Revealing pathways from payments for ecosystem services to socioeconomic outcomes. Sci. Adv. 2018, 4, 1-8. [CrossRef]

2. Wunder, S.; Engel, S.; Pagiola, S. Taking stock: A comparative analysis of payments for environmental services programs in developed and developing countries. Ecol. Econ. 2008, 65, 834-852. [CrossRef]

3. Engel, S.; Pagiola, S.; Wunder, S. Designing payments for environmental services in theory and practice: An overview of the issues. Ecol. Econ. 2008, 65, 663-674. [CrossRef]

4. Naeem, S.; Ingram, J.C.; Varga, A.; Agardy, T.; Barten, P.; Bennett, G.; Bloomgarden, E.; Bremer, L.L.; Burkill, P.; Cattau, M.; et al. Environment and Development. Get the science right when paying for nature's services. Science 2015, 347, 1206-1207. [CrossRef]

5. Sommerville, M.M.; Jones, J.P.G.; Milner-Gulland, E.J. A revised conceptual framework for payments for environmental services. Ecol. Soc. 2009, 14. [CrossRef]

6. Liu, J.; Li, S.; Ouyang, Z.; Tam, C.; Chen, X. Ecological and socioeconomic effects of China's policies for ecosystem services. Proc. Natl. Acad. Sci. USA 2008, 105, 9477-9482. [CrossRef]

7. Fang, B.; Tan, Y.; Li, C.; Cao, Y.; Liu, J.; Schweizer, P.J.; Shi, H.; Zhou, B.; Chen, H.; Hu, Z. Energy sustainability under the framework of telecoupling. Energy 2016, 106, 253-259. [CrossRef]

8. Liu, C.; Lü, J.; Yin, R. An estimation of the effects of China's forestry programs on farmers' income. An Integr. Assess. China's Ecol. Restor. Programs 2009, 201-218. [CrossRef]

9. Kates, R.W.; Clark, W.C.; Corell, R.; Hall, J.M.; Jaeger, C.C.; Lowe, I.; McCarthy, J.J.; Schellnhuber, H.J.; Bolin, B.; Dickson, N.M.; et al. Environment and development: Sustainability science. Science 2001, 292, 641-642. [CrossRef]

10. Ferraro, P.J.; Hanauer, M.M. Quantifying causal mechanisms to determine how protected areas affect poverty through changes in ecosystem services and infrastructure. Proc. Natl. Acad. Sci. USA 2014, 111, 4332-4337. [CrossRef]

11. Law, E.A.; Ferraro, P.J.; Arcese, P.; Bryan, B.A.; Davis, K.; Gordon, A.; Holden, M.H.; Iacona, G.; Marcos Martinez, R.; McAlpine, C.A.; et al. Projecting the performance of conservation interventions. Biol. Conserv. 2017, 215, 142-151. [CrossRef]

12. Kotchen, M.J.; Young, O.R. Meeting the challenges of the anthropocene: Towards a science of coupled human-biophysical systems. Glob. Environ. Change 2007, 17, 149-151. [CrossRef] 
13. Schlüter, M.; McAllister, R.R.J.; Arlinghaus, R.; Bunnefeld, N.; Eisenack, K.; Hölker, F.; Milner-Gulland, E.J.; Müller, B.; Nicholson, E.; Quaas, M.; et al. New horizons for managing the environment: A review of coupled social-ecological systems modeling. Nat. Resour. Model. 2012, 25, 219-272. [CrossRef]

14. Liu, J.; Dietz, T.; Carpenter, S.R.; Alberti, M.; Folke, C.; Moran, E.; Pell, A.N.; Deadman, P.; Kratz, T.; Lubchenco, J.; et al. Complexity of Coupled Human and Natural Systems. Science 2007, 317, 1513-1516. [CrossRef]

15. Liu, J.; Hull, V.; Batistella, M.; Defries, R.; Dietz, T.; Fu, F.; Hertel, T.W.; Izaurralde, R.C.; Lambin, E.F.; Li, S.; et al. Framing Sustainability in a Telecoupled World. Ecol. Soc. 2013, 18, 26. [CrossRef]

16. da Silva, R.; Batistella, M.; Dou, Y.; Moran, E.; Torres, S.; Liu, J. The Sino-Brazilian Telecoupled Soybean System and Cascading Effects for the Exporting Country. Land 2017, 6, 53. [CrossRef]

17. Liu, J.; Hull, V.; Moran, E.; Nagendra, H.; Swaffield, S.R.; Turner II, B.L. Applications of the Telecoupling Framework to Land-Change Science. Rethink. Glob. Land Use Urban Era 2014, 14, 119-140. [CrossRef]

18. Sun, J.; TONG, Y.X.; Liu, J. Telecoupled land-use changes in distant countries. J. Integr. Agric. 2017, 16, 368-376. [CrossRef]

19. Liu, J. Forest Sustainability in China and Implications for a Telecoupled World. Asia Pac. Policy Stud. 2014, 1, 230-250. [CrossRef]

20. Deines, J.M.; Liu, X.; Liu, J. Telecoupling in urban water systems: An examination of Beijing's imported water supply. Water Int. 2016, 41, 251-270. [CrossRef]

21. Liu, J.; Yang, W.W. Integrated assessments of payments for ecosystem services programs. Proc. Natl. Acad. Sci. USA 2013, 110, 16297-16298. [CrossRef]

22. Liu, J.; Yang, W.; Li, S. Framing ecosystem services in the telecoupled Anthropocene. Front. Ecol. Environ. 2016, 14, 27-36. [CrossRef]

23. Li, J.; Feldman, M.W.; Li, S.; Daily, G.C. Rural household income and inequality under the Sloping Land Conversion Program in western China. Proc. Natl. Acad. Sci. USA 2011, 108, 7721-7726. [CrossRef]

24. Cao, S.; Wang, X.; Song, Y.; Chen, L.; Feng, Q. Impacts of the Natural Forest Conservation Program on the livelihoods of residents of Northwestern China: Perceptions of residents affected by the program. Ecol. Econ. 2010, 69, 1454-1462. [CrossRef]

25. Liu, J.; Diamond, J. Revolutionizing China's Environmental Protection. Science 2008, 319, 37-38. [CrossRef]

26. Uchida, E.; Xu, J.; Rozelle, S. Grain for Green: Cost-Effectiveness and Sustainability of China's Conservation Set-Aside Program. Land Econ. 2005, 81, 247-264. [CrossRef]

27. Zhang, H.; Peng, D.; Deng, R.; Wang, D.; Han, Y. Dynamic Change of Land Use in Qilian Mountains Based on Time-series Landsat Image. Beijing Gongye Daxue Xuebao/Journal Beijing Univ. Technol. 2017, 43, 665-676. [CrossRef]

28. Wu, Z.L.; Jia, W.X.; Zhao, Z.; Zhang, Y.S.; Liu, Y.R.; Chen, J.H. Spatial-temporal variations of vegetation and its correlation with climatic factors in Qilian Mountains from 2000 to 2012. Arid L. Geogr. 2015, 38. [CrossRef]

29. Tonini, F.; Liu, J. Telecoupling toolbox: Spatially explicit tools for studying telecoupled human and natural systems. Ecol. Soc. 2017, 22. [CrossRef]

30. Guerry, A.D.; Polasky, S.; Lubchenco, J.; Chaplin-Kramer, R.; Daily, G.C.; Griffin, R.; Ruckelshaus, M.; Bateman, I.J.; Duraiappah, A.; Elmqvist, T.; et al. Natural capital and ecosystem services informing decisions: From promise to practice. Proc. Natl. Acad. Sci. USA 2015, 112, 7348-7355. [CrossRef]

31. Liu, J. Integration across a metacoupled planet. Ecol. Soc. 2017, 22, 1-37. [CrossRef]

32. Qiu, G.Y.; Yin, J.; Tian, F.; Geng, S. Effects of the "Conversion of Cropland to Forest and Grassland Program" on the Water Budget of the Jinghe River Catchment in China. J. Environ. Qual. 2011, 40, 1745. [CrossRef]

33. Turner, B.L.; Kasperson, R.E.; Matson, P.A.; McCarthy, J.J.; Corell, R.W.; Christensen, L.; Eckley, N.; Kasperson, J.X.; Luers, A.; Martello, M.L.; et al. A framework for vulnerability analysis in sustainability science. Proc. Natl. Acad. Sci. USA 2003, 100, 8074-8079. [CrossRef] [PubMed]

34. Folke, C.; Jansson, Å.; Rockström, J.; Olsson, P.; Carpenter, S.R.; Stuart Chapin, F.; Crépin, A.S.; Daily, G.; Danell, K.; Ebbesson, J.; et al. Reconnecting to the biosphere. Ambio 2011, 40, 719-738. [CrossRef]

35. Liu, J.; Hull, V.; Luo, J.; Yang, W.; Liu, W.; Viña, A.; Vogt, C.; Xu, Z.; Yang, H.; Zhang, J.; et al. Multiple telecouplings and their complex interrelationships. Ecol. Soc. 2015, 20. [CrossRef]

36. Yao, S.; Guo, Y.; Huo, X. An empirical analysis of the effects of China's land conversion program on farmers' income growth and labor transfer. Environ. Manage 2009, 159-173. [CrossRef]

37. Yao, S.; Li, H.; Liu, G. Agricultural productivity changes induced by the sloping land conversion program: An analysis of wuqi county in the loess plateau region. Environ. Manage 2009, 219-233. [CrossRef]

38. Lin, Y.; Yao, S. Impact of the Sloping Land Conversion Program on rural household income: An integrated estimation. Land Use Policy 2014, 40, 56-63. [CrossRef] 